\title{
Effect of the extract from salvia miltiorrhiza radix (SMR) on skeletal muscle ischemia and reperfusion injury in rabbits
}

\author{
Daping Yang MD, Steven F Morris MSc MD FRCSC \\ Department of Surgery and Anatomy, Dalhousie University, Halifax, Nova Scotia
}

\begin{abstract}
D Yang, SF Morris. Effect of the extract from salvia miltiorrhiza radix (SMR) on skeletal muscle ischemia and reperfusion injury in rabbits. Can J Plast Surg 1997;5(3):171-175. The extract of salvia miltiorrhiza radix (SMR) is a well known Chinese herbal medicine known as danshen. It has been found in several experimental studies, published mostly in China, to have antioxidant properties. The purpose of this experiment was, therefore, to compare the effects of danshen injection with those of superoxide dismutase (SOD) and mannitol on skeletal muscle ischemia and reperfusion injury in rabbits. The authors used a rabbit limb replantation model subjected to $5 \mathrm{~h}$ of global ischemia. Immediately before reperfusion, the animals received SOD $(16,000 \mathrm{U} / \mathrm{kg})$, mannitol $(1 \mathrm{~g} / \mathrm{kg})$ or danshen injection $(2 \mathrm{~g} / \mathrm{kg})$ intravenously. Both danshen and mannitol significantly increased limb survival $(\mathrm{P}<0.01)$. Increased limb survival was observed in the SOD-treated group compared with the saline-treated group $(\mathrm{P}<0.05)$ but not with the ischemic group $(\mathrm{P}>0.05)$. Light and transmission electron microscopy revealed that the pathologic and ultrastructural changes in skeletal muscles, which were subjected to $5 \mathrm{~h}$ of ischemia followed by $2 \mathrm{~h}$ of reperfusion, were reduced with SOD, mannitol and danshen injection. These results suggest that the hydroxyl radical seems to be the most important factor in ischemia and reperfusion injury to skeletal muscle and that danshen, like mannitol, may have a role in antioxidation as a hydroxyl radical scavenger.
\end{abstract}

Key Words: Antioxidant, Ischemia/reperfusion injury, Rabbit, Salvia miltiorrhiza radix

Effet d'un extrait de racine de salvia miltiorrhiza sur l'ischémie du muscle squelettique et la lésion de reperfusion chez le lapin

RÉSUMÉ : L'extrait de racine de salvia miltiorrhiza est bien connu comme plante médicinale en Chine, sous le nom de danshen. Selon plusieurs études expérimentales publiées surtout en Chine, cette plante aurait des propriétés antioxydantes. Le but de l'expérience était donc de comparer les effets d'une injection de danshen à ceux de la superoxyde dismutase (SOD) et du mannitol sur l'ischémie du muscle squelettique et sur la lésion de reperfusion chez le lapin. Les auteurs ont utilisé un modèle de réimplantation de membre chez le lapin soumis à une ischémie globale de cinq heures. Immédiatement avant la reperfusion, les animaux ont reçu une injection de SOD $(16000 \mathrm{U} / \mathrm{kg}) \mathrm{de} \mathrm{mannitol}(1 \mathrm{~g} / \mathrm{kg}) \mathrm{ou} \mathrm{de}$ danshen $(2 \mathrm{~g} / \mathrm{kg})$ par voie intraveineuse. Le danshen et le mannitol ont significativement accru la survie du membre $(p<0,01)$. Une survie accrue du membre a été observée dans le groupe traité à la SOD en comparaison avec le groupe traité par sérum physiologique $(p<0,05)$, mais non en comparaison avec le groupe ischémique $(p>0,05)$. Les examens à la microscopie classique et électronique ont révélé que les changements pathologiques et ultrastructurels survenus dans le muscle squelettique soumis à cinq heures d'ischémie puis à deux heures de reperfusion ont été atténués par l'injection de SOD, de mannitol et de danshen. Ces résultats donnent à penser que le radical hydroxyle semble être le plus important facteur dans l'ischémie et la lésion de reperfusion du muscle squelettique et que le danshen, comme le mannitol, pourrait exercer un rôle dans l'antioxydation comme piégeur des radicaux hydroxyle.

$\mathrm{T}$ he development of microsurgical techniques for replantation of amputated digits and limbs has led to longer periods of ischemia in the clinical setting. In addition, transplantation of skeletal muscle is employed to treat facial paralysis and Volkmann's ischemic contracture. To restore function to replanted extremities and transplanted muscle,

Correspondence and reprints: Dr Steven F Morris, Head, Division of Plastic Surgery, Room 4929 NH1, Queen Elizabeth II Health Sciences Centre, 1796 Summer Street, Halifax, Nova Scotia B3H 2 A7.

Telephone 902-473-7054, fax 902-473-8773, e-mail sfmorris@is.dal.ca not only should the ischemic period be shorter than that required for successful replantation and transplantation, but also reperfusion injury of skeletal muscle should be avoided. White cell inhibitors, enriched substrates and controlled rates of reperfusion, or combinations of these, have been shown to improve muscle viability and recover potentially viable muscle, oxygen and hydroxyl radical scavengers after prolonged ischemia and variable periods of reperfusion (1-4).

Salvia miltiorrhizae radix (Chinese crude drug named 'danshen') has been used in China as a therapeutic modality for 
heart disease, particularly angina pectoris and myocardial infarction (5). The chemical composition of danshen has been actively investigated. The organic extract of danshen is rich in diterpene quinones (6), some of which have been isolated or synthesized and their pharmacological effects reported in preliminary studies on myocardial ischemia/reperfusion injury $(7,8)$. In a previous report from our laboratory we showed a protective effect of danshen on island skin flap, limb model ischemia and reperfusion injury $(9,10)$. However, there have been no reports concerning the action of danshen on skeletal muscle. The purpose of this experiment was, therefore, to evaluate the effects of danshen compared with those of the superoxide radical scavenger superoxide dismutase (SOD) and of the hydroxyl radical scavenger mannitol on skeletal muscle ischemia and reperfusion injury in rabbits, through light and electron microscopic observations and limb survival analyses.

\section{ANIMALS AND METHODS}

Model: The operating room temperature was $20^{\circ} \mathrm{C}$. The rabbits were anesthetized with sodium pentobarbital intravenously via the ear vein $(30 \mathrm{mg} / \mathrm{kg})$. The limb preparation has been described previously (4). The lower abdomen and left hindlimb were shaved and sterilized with iodine. A laparotomy was performed using a lower midline incision, and the infrarenal aorta and iliac arteries were dissected. The internal iliac arteries were ligated bilaterally, and the left femoral artery was isolated through groin incision. The left hindlimb was made ischemic by use of microvascular clamps on the left iliac and femoral arteries. Bloodflow to the ischemic left hindlimb was assessed by Doppler probe before and after clamping. The abdominal and groin incisions were closed and all animals were subjected to $5 \mathrm{~h}$ of complete ischemia.

Research design: Fifty male New Zealand white rabbits weighing between 2.5 and $3.0 \mathrm{~kg}$ were randomly separated into five groups of 10 (groups A, B, C, D and E). The experiment was carried out in two parts. In part A, the effects of SOD, mannitol and danshen injection were compared with those of saline infusion. In part B, the microscopic and ultrastructural effects of SOD, mannitol and danshen injection were compared with saline treated and untreated controls. All groups were subjected to $5 \mathrm{~h}$ of global ischemia. Group A was the control group. Groups B, C, D and E were immediately treated with saline, SOD, mannitol and danshen injections, respectively, just before reperfusion.

Before reperfusion, the rabbits were anaesthetized again. Abdominal and groin incisions were re-opened. In all groups except $\mathrm{A}$, the left inferior epigastric artery was dissected, and the proximal stump was cannulated using a 22-gauge catheter.

At the end of the $5 \mathrm{~h}$ ischemic period, the left gastrocnemii were obtained in group A and then reperfusion of all left hind limbs was achieved by removing both iliac and femoral clamps. In the meantime, an intra-arterial infusion of saline, SOD (16,000 U/kg), mannitol (1 g/kg, $1 \mathrm{~g} / 5 \mathrm{~mL})$ and danshen $(2 \mathrm{~g} / \mathrm{kg})$, each in $15 \mathrm{~mL}$ saline solution, was given with a hand-held syringe to groups B, C, D and E, respectively, steadily over 20 mins. The catheter was then removed, the in- ferior epigastric artery was ligated and the incisions were closed. In all animals, reperfusion was assessed by a Doppler probe. At the end of the $2 \mathrm{~h}$ reperfusion, the left gastrocnemii were obtained in groups B, C, D and E. Muscle biopsies for light and transmission electron microscopy (TEM) were taken from the middle of the gastrocnemii. Biopsy tissues for light microscopy were stained with hematoxylin and eosin to observe the general structure of ischemic muscles and stained by von Kossa's method (11) to observe calcium deposits.

Specimens for TEM were immediately immersed in $2 \%$ glutaraldehyde fixative solution buffered to $\mathrm{pH} 7.4$ with $0.2 \mathrm{M}$ sodium cacodylate buffer. After fixation, the tissue was post-fixed for $2 \mathrm{~h}$ in $1 \%$ osmium tetroxide in cacodylate buffer at $\mathrm{pH}$ 7.4. After dehydration through a graduated alcohol series the tissue was embedded in fresh Epon 812. Sections were cut on a Porter-1 ultramicrotome, mounted on copper grids and stained with uranyl acetate and lead citrate, and examined with a Hitachi H600 electron microscope (California).

The appearance of the left limb was recorded daily, and the animals were sacrificed at seven days. Determination of left limb survival or necrosis was made clinically. Limb survival was observed to be all or none: limbs that survived were pink with trace edema and those that failed were necrotic and cadaveric.

Results were analyzed using the $\chi^{2}$ test for heterogeneity or independence. $\mathrm{P}<0.05$ was accepted as statistical significance.

\section{Part A}

\section{RESULTS}

Survival: The increased rate of survival in the danshentreated group (E) was significant when compared with the ischemic (group A) $(\mathrm{P}<0.05)$ and saline-treated $(\mathrm{B})$ groups $(\mathrm{P}<0.05)$ (Table 1). The increased survival in the mannitoltreated group was also significant compared with the ischemic $(\mathrm{p}<0.05)$ and saline-treated groups $(\mathrm{P}<0.05)$. In the SOD-treated group $(\mathrm{C})$, the increased survival was significant compared with group $\mathrm{B}(\mathrm{P}<0.05)$ but not with group $\mathrm{A}$ $(\mathrm{P}>0.05)$. There were no statistically significant differences among groups $\mathrm{C}, \mathrm{D}$ and $\mathrm{E}(\mathrm{P}>0.05)$.

\section{Part B}

Microscopy: In group A, muscle fibre structures were loose with wide intermuscular spaces. Some cells were vacuolated and denatured with cloudy swelling.

In group B, the following features were noted: disarrangement of fibrillar structure, focal necrosis, coagulation necrosis in some cells, leukocyte infiltration and calcium deposits in partial areas.

No definite changes were found in groups C, D or E, but there were intercellular edema and myofibrillar disorder.

Electron microscopy: After $5 \mathrm{~h}$ of ischemia, moderate and severe muscle injury (12) was observed in group A. The sarcoplasmic reticulum and mitochondria were remarkably swollen with outer membranes intact. The mitochondrial matrices were lucent, and glycogen granules were absent. Floc- 
TABLE 1: Survival of limbs

\begin{tabular}{lcc}
\hline Group & Number & Percentage \\
\hline A - Untreated controls & $2 / 10$ & 20 \\
B - Saline-treated limbs & $1 / 10$ & 10 \\
C - Super oxide dismutase- & $6 / 10$ & 60 \\
$\quad$ treated limbs & & \\
D - Mannitol-treated limbs & $7 / 10$ & 70 \\
E - Danshen-treated limbs & $8 / 10$ & 80 \\
\hline
\end{tabular}
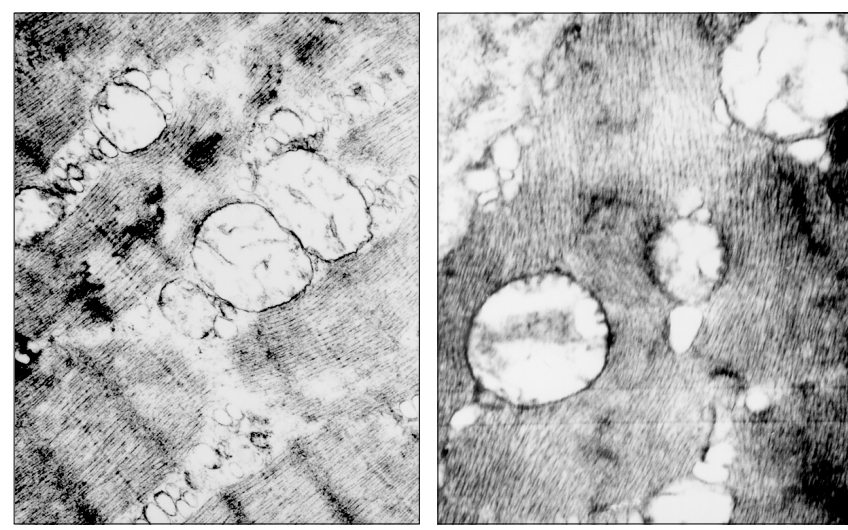

Figure 1) Ultrastructural appearance of rabbit gastrocnemius muscle after $5 \mathrm{~h}$ of ischemia before reperfusion (left $\times 20,000$; right $\times 30,000$ )

culent electron densities were seen in some mitochondria. The mitochondrial cristae were disordered with many breaks (Figure 1).

After $2 \mathrm{~h}$ of reperfusion following $5 \mathrm{~h}$ of ischemia, lethal muscle injury was seen in group B. The myofibrils and sarcomeres were disordered. Severe intracellular edema was seen. The mitochondria were extremely swollen with ruptured outer membranes, broken cristae and lost matrical density. Vacuolated giant mitochondria were observed. Some mitochondria contained large dense calcium deposits. Swelling of microvascular endothelial cells and microthrombi formation were seen (Figure 2).

Moderate muscle injury was observed in the SOD-treated group. The mitochondria cristae were disorganized with some breaks. The mitochondrial matrices were lucent with absent granules (Figure 3).

Mild and moderate muscle injury was seen in the mannitol- and danshen-treated groups. The mitochondria were moderately swollen and showed disorganized cristae with occasional breaks and relatively clear matrices. Glycogen granules were absent. The outer membranes of the mitochondria remained intact (Figures 4,5).

\section{DISCUSSION}

Ischemia-induced reperfusion injury occurs in skeletal muscle and is thought to be due, at least in part, to the release of oxygen derived free radicals during the reperfusion period.
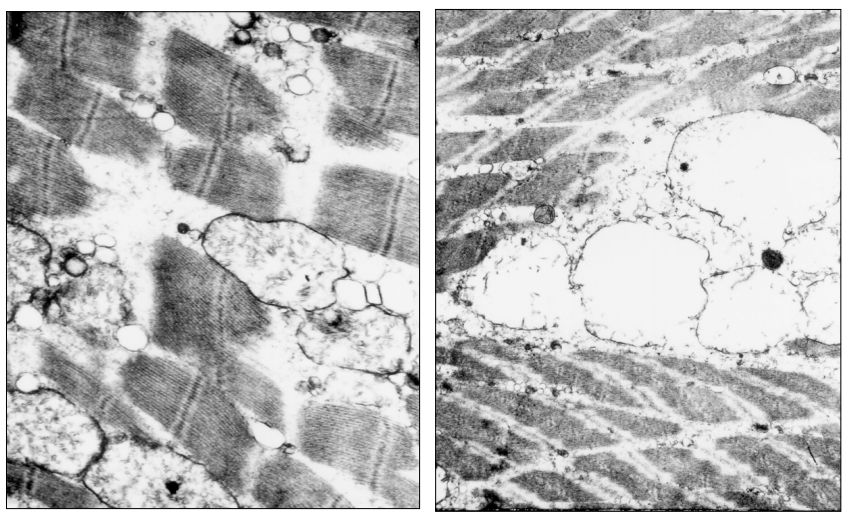

Figure 2) Ultrastructural appearance of rabbit gastrocnemius muscle after $5 \mathrm{~h}$ of ischemia and $2 \mathrm{~h}$ of reperfusion in saline-treated group (left $\times 20,000$; right $\times 30,000$ )
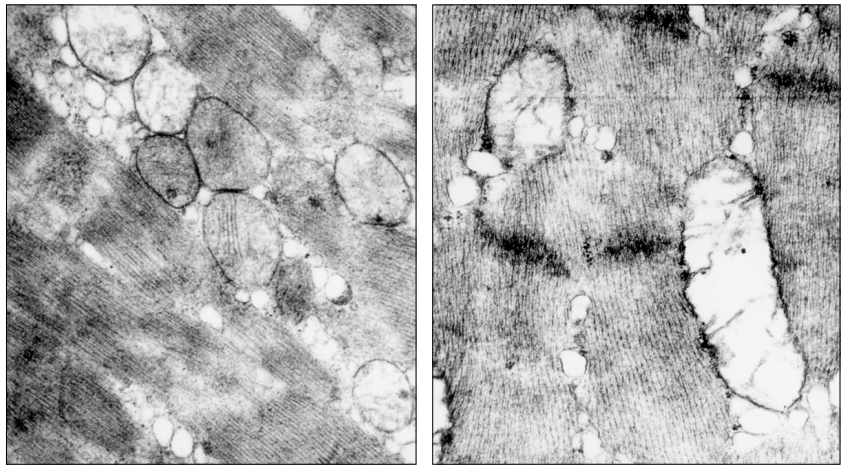

Figure 3) Ultrastructural appearance of rabbit gastrocnemius muscle after 5 h of ischemia and $2 h$ of reperfusion in the superoxide dismutasetreated group (left $\times 20,000$; right $\times 30,000)$

Many agents modulate the biochemical events of ischemia and reperfusion and some have been found to increase experimental ischemic limb and flap survival.

In the present study, we have shown that a statistically significant improvement in survival of hindlimbs subjected to $5 \mathrm{~h}$ of ischemia can be achieved by the intra-arterial perfusion of SOD, mannitol and danshen compared with saline. Moderate and reversible muscle injury was observed by electron microscopy after $5 \mathrm{~h}$ of ischemia. Principal morphological changes included swollen mitochondria and sarcoplasmic reticulum, lucent mitochondrial matrices with absent granules and breaks, and disordered mitochondrial cristae with some breaks. These mitochondrial alterations were the earliest ultrastructural signs of fibre damage in ischemic muscle. Reperfusion aggravated the muscle injury with severe intracellular edema, dense calcium deposits and swollen mitochondria with ruptured outer membrane and broken cristae, which suggested that cell injury was irreversible and lethal. Swelling of endothelial cells and formation of microthrombi were also seen after $2 \mathrm{~h}$ of reperfusion following $5 \mathrm{~h}$ of ischemia. The effect of mannitol on ultrastructural changes was better than that of SOD. These results suggest that the hydroxyl radical seems to play a major role in skeletal muscle ischemia and reperfusion injury $(13,14)$. The explanation of 

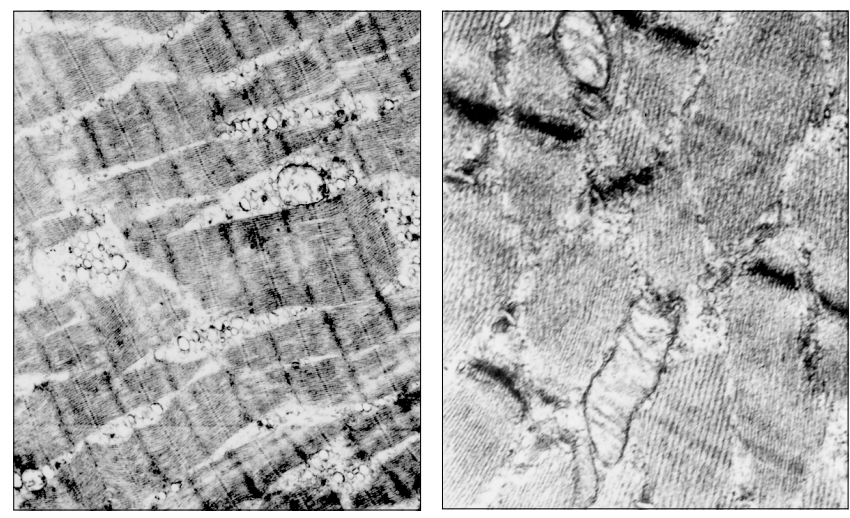

Figure 4) Ultrastructural appearance of rabbit gastrocnemius muscle after $5 \mathrm{~h}$ of ischemia and $2 \mathrm{~h}$ of reperfusion in mannitol-treated group (left $\mathrm{x} 15,000$; right $\mathrm{x} 30,000$ )

these results is as follows: both reperfusion injury and hydrogen peroxide can be toxic to tissues but individually they are generally not too toxic. However, when oxygen and peroxide combine in the Haber-Weiss reaction, a very toxic, highly reactive compound, the hydroxyl radical, is generated. This toxic oxygen metabolite causes cellular damage primarily through the peroxidation of cell and mitochondrial membranes (15). The hydroxyl radical attacks and damages a membrane-bound polyunsaturated fatty acid. The end products, malondialdehyde (MDA) and hydroperoxide, are a result of autoxidation of membranous fatty acids $(16,17)$. We have previously shown that MDA levels, as indicators of oxygen radical production in the plasma, from ischemic and reperfused limbs were significantly higher than those from single ischemic limbs $(\mathrm{P}<0.01)$. Mannitol- and danshentreated limbs produced significantly less MDA than ischemic and reperfused limbs $(\mathrm{P}<0.01)(10)$.

The mechanism for the effect of danshen on this ischemia and reperfusion model remains unknown. The chemical composition of danshen has been a subject of active inquiry. Structurally, danshen does not strongly resemble any class of known antioxidants. However, it does possess unsaturated rings, which are common features in antioxidants (eg, vitamin $\mathrm{E}$ and carotenoids) (18). We speculate that danshen, like

\section{REFERENCES}

1. Lee KR, Cronenwett JL, Shlafer M, Corpron C, Zelenock GB. Effect of superoxide dismutase plus catalase on calcium transport in ischemic and reperfused skeletal muscle. J Surg Res 1987;42:24-32.

2. Perry MO, Fantini G. Ischemia: Profile of an enemy. Reperfusion injury of skeletal muscle. J Vasc Surg 1987;6:231-4.

3. Belkin M, LaMorte WL, Wright JG, Hobson RW II. The role of leukocytes in the pathophysiology of skeletal muscle ischemic injury. J Vasc Surg 1989;10:14-9.

4. Quiñones-Baldrich WJ, Chervu A, Hernandez JJ, Colburn M, Moore WS. Skeletal muscle function after ischemia: 'No reflow' versus reperfusion injury. J Surg Res 1991;51:5-12.

5. Chang HM, But PPH. Danshen. In: Chang HM, But PPH, eds. Pharmacology and Applications of Chinese Materia Medica. Singapore: World Scientific Publishing Co, 1986:225-68.

6. Chang HM, Chen KP, Choang TF, et al. Structure elucidation and total synthesis of new tanshinones isolated from salvia miltiorrhiza bunge (danshen). J Org Chem 1990;55:3537-43.
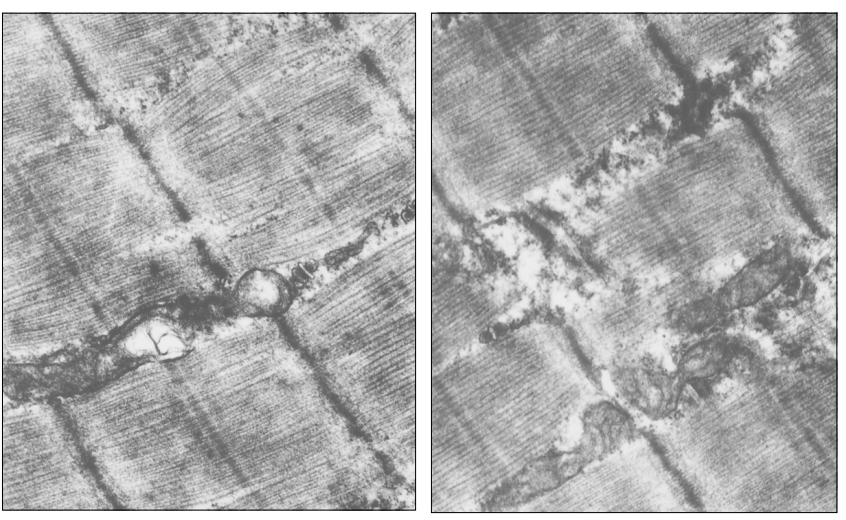

Figure 5) Ultrastructural appearance of rabbit gastrocnemius muscle after $5 \mathrm{~h}$ of ischemia and $2 \mathrm{~h}$ of reperfusion in danshen-treated group (left and right $\mathrm{x} 30,000$ )

mannitol, may play a role in antioxidation as a hydroxyl radical scavenger.

There have been other speculations that the aqueous extract of SMR may inhibit other sources of oxygen radical formation in pathways, such as those in leukocytes, impaired mitochondria and in oxidation of catecholamines $(19,20)$. $\mathrm{Wu}$ et al (18) demonstrated that the aqueous extract from SMR, sodium tanshinone IIA solfonate, is a cardioprotector both in cultured human vascular endothelial cells and in the rabbit heart during ischemia/reperfusion. One may further speculate that there is a cause-and-effect relationship between the endothelial protective effect and prevention of the so-called 'no-reflow' phenomenon exhibited by danshen, while endothelial cells are likely to be more important sites and targets of oxygen radical damage than the skeletal muscle. The earliest changes noted following an ischemic insult in skeletal muscle involved a breakdown of endothelial integrity with an increase in microvascular permeability (21). These changes precede structural alterations in the muscle cell (22).

In summary, we conclude that a protective effect of danshen on ischemia/reperfusion injury is suggested in this replantation model. However, the precise mechanism of the salvage effect remains to be determined.

7. Yagi A, Fujimoto K, Tanonaka K, Hirai K, Takeo S. Possible active components of tan-shen (salvia miltiorrhiza) for protection of the myocardium against ischemia-induced derangements. Planta Med 1989;55:51-4.

8. Takeo S, Tanonaka K, Hirai K, et al. Beneficial effect of tan-shen, an extract from the root of salvia, on posthypoxic recovery of cardiac contractile force. Biochem Pharmacol 1990;40:1137-43.

9. Yang DP. Prevention of reperfusion injury of an ischemic flap: an experimental study. Chin J Plast Surg 1992;8:216-7.

10. Yang DP. Experimental study of the ischemia reperfusion injury in limbs and its protection in rabbits. Chin J Hand Surg 1992;8:222-4.

11. McManus JFA, Mowry RW, eds. Staining Methods. New York: Hoeber Medical Division, Harper \& Row, 1965:201.

12. Morris SF, Pang CY, Lofchy NM, et al. Deferoxamine attenuates ischemia induced reperfusion injury in the skin and muscle of myocutaneous flaps in the pig. Plast Reconstr Surg 1993;92:120-32.

13. Blebea J, Kerr JC, Hobson RW, Padberg FT. The effects of oxygen free radical scavengers on skeletal muscle ischemia and reperfusion injury. Curr Surg 1987;44:396-8. 
14. Oredsson S, Plate G, Quarfordt P. Experimental evaluation of oxygen free radical scavengers in the prevention of reperfusion injury in skeletal muscle. Eur J Surg 1994;160:97-103.

15. McCord JM. Oxygen-derived free radicals in post-ischemic tissue injury. N Engl J Med 1985;312:159-63.

16. Halliwell B, Gutteridge JMC. Free Radicals in Biology and Medicine. Oxford: Oxford University Press, 1985.

17. Halliwell B. Oxygen radicals: A commonsense look at their nature and medical importance. Med Biol 1984;62:71.

18. Wu TW, Zeng LH, Fung KP, Wu J, Pang H. Effects of sodium tanshinone IIa sulfonte in the rabbit myocardium and on human cardiomyocytes and vascular endothelial cells. Biochem Pharmacol 1993;46:2327-32.

19. Ambrosiom G, Chiariells M. Myocardial reperfusion injury: mechanisms and management - a review. Am J Med 1991;91:86-8.

20. Downey JM, Miura T, Eddy LJ, et al. Xanthine oxidase is not a source of free radials in the ischemic rabbit heart. J Mol Cell Cardiol 1987;19:1053-60.

21. Suval WD, Hobson RW II, Boric MP, Ritter AB, Duran WD. Assessment of ischemia-reperfusion injury in skeletal muscle by macromolecular clearnie. J Surg Res 1987;42:550.

22. Suval WD, Duran WN, Boric MP, Hobson RW II, Berendsen $\mathrm{PB}$, Ritter AB. Microvascular transport and endothelial cell alterations preceding skeletal muscle damage in ischemia and reperfusion injury. Am J Surg 1987;154:211-8. 